\title{
Cell-attached single-channel recordings in intact prefrontal cortex pyramidal neurons reveal compartmentalized D1/D5 receptor modulation of the persistent sodium current
}

\author{
Natalia Gorelova and Jeremy K. Seamans* \\ Department of Psychiatry and Brain Research Centre, University of British Columbia, Vancouver, BC, Canada
}

Edited by:

Allan T. Gulledge, Geisel School of

Medicine at Dartmouth, USA

\section{Reviewed by:}

Bruce P. Bean, Harvard Medical

School, USA

Christian Alzheimer, Universität

Erlangen-Nürnberg, Germany

${ }^{*}$ Correspondence:

Jeremy K. Seamans, Department of

Psychiatry and Brain Research

Centre, University of British

Columbia, 2211 Wesbrook Mall,

Vancouver, BC V6T 2B5, Canada e-mail: jeremy.seamans@ubc.ca
The persistent $\mathrm{Na}^{+}$current $\left(/_{\mathrm{Nap}}\right)$ is believed to be an important target of dopamine modulation in prefrontal cortex (PFC) neurons. While past studies have tested the effects of dopamine on $/ \mathrm{Nap}$, the results have been contradictory largely because of difficulties in measuring / Nap using somatic whole-cell recordings. To circumvent these confounds we used the cell-attached patch-clamp technique to record single $\mathrm{Na}^{+}$channels from the soma, proximal dendrite (PD) or proximal axon (PA) of intact prefrontal layer $V$ pyramidal neurons. Under baseline conditions, numerous well resolved $\mathrm{Na}^{+}$channel openings were recorded that exhibited an extrapolated reversal potential of $73 \mathrm{mV}$, a slope conductance of 14-19 pS and were blocked by tetrodotoxin (TTX). While similar in most respects, the propensity to exhibit prolonged bursts lasting $>40 \mathrm{~ms}$ was many fold greater in the axon than the soma or dendrite. Bath application of the D1/D5 receptor agonist SKF81297 shifted the ensemble current activation curve leftward and increased the number of late events recorded from the PD but not the soma or PA. However, the greatest effect was on prolonged bursting where the D1/D5 receptor agonist increased their occurrence 3 fold in the PD and nearly 7 fold in the soma, but not at all in the PA. As a result, D1/D5 receptor activation equalized the probability of prolonged burst occurrence across the proximal axosomatodendritic region. Therefore, D1/D5 receptor modulation appears to be targeted mainly to $\mathrm{Na}^{+}$channels in the PD/soma and not the PA. By circumventing the pitfalls of previous attempts to study the D1/D5 receptor modulation of $/$ Nap, we demonstrate conclusively that D1/D5 receptor activation can increase the /Nap generated proximally, however questions still remain as to how D1/D5 receptor modulates $\mathrm{Na}^{+}$currents in the more distal initial segment where most of the / $/$ ap is normally generated.

Keywords: prefrontal cortex, $\mathrm{Na}^{+}$channels, single channel recordings, persistent $\mathrm{Na}^{+}$current, dopamine, D1/D5 receptors

\section{INTRODUCTION}

Dopamine modulates a number of cognitive functions mediated by the prefrontal cortex (PFC) while dysregulation of the mesocortical dopamine system is thought to occur in psychiatric conditions. One current that plays an important role in shaping PFC activity is the persistent $\mathrm{Na}^{+}$current $\left(I_{\mathrm{Nap}}\right) . I_{\mathrm{Nap}}$ is similar to the fast transient $\mathrm{Na}^{+}$current but tends to activate at a lower voltage and inactivates more slowly (French and Gage, 1985; Patlak and Ortiz, 1985; French et al., 1990; Alzheimer et al., 1993; Taylor, 1993; Astman et al., 2006). I Nap strongly regulates intrinsic excitability, membrane oscillations (White et al., 1998; Hu et al., 2009), synaptic amplification (Stuart and Sakmann, 1995) and persistent activity (Durstewitz et al., 2000) while computational modeling has suggested that $I_{\text {Nap }}$ neuromodulation can profoundly affect overall network activity (Durstewitz et al., 2000; Durstewitz and Seamans, 2008).

A number of studies have reported that dopamine modulates $I_{\text {Nap }}$ in PFC neurons but the issue has been quite contentious.
The inconsistencies may stem largely from the limitations of the techniques commonly used to study $I_{\text {Nap }}$. In the initial papers, sharp intracellular pipettes were used (Geijo-Barrientos and Pastore, 1995; Yang and Seamans, 1996) which create a considerable shunt around the electrode and extremely poor voltage control. A subsequent study used whole-cell patchclamp recordings (Gorelova and Yang, 2000) which provided better, but still imperfect voltage control given the expansive dendritic arbor of deep layer PFC pyramidal neurons. One way to circumvent this problem, employed by Maurice et al. (2001) was to use dissociated cells where the neurites were enzymatically and mechanically severed. However, given the diameter of the axon relative to the soma, if the axon is $>10$ um in length, it's voltage is still difficult to control from a somatic electrode (White et al., 1995) while a second drawback is that key intracellular cascades could be disrupted or lost in the dissociation procedure which could be potentially serious given the dramatic differences in $I_{\text {Nap }}$ in the presence vs. absence of 
various intracellular molecules (Ma et al., 1994, 1997; Fleidervish et al., 2008). A final problem is that each $\mathrm{Na}^{+}$channel subtype tends to be distributed nonuniformly throughout the axonalsomato-dendritic region (Raman and Bean, 1997; Smith et al., 1998; Caldwell et al., 2000; Goldin, 2001; Rush et al., 2005; Osorio et al., 2010). Since all studies of dopamine modulation of $I_{\text {Nap }}$ to date have recorded exclusively from the soma, the issue of compartmentalized modulation has not been experimentally addressed.

The only solution to this myriad of potential artifacts and complications is to employ a technique where one can record in different cellular compartments with perfect voltage control while leaving intracellular signaling cascades untouched. This is possible with the cell-attached recording configuration. In the present study we performed cell-attached recordings from the soma, proximal apical dendrite (PD) and the proximal axon (PA) of deep layer PFC neurons. Using this approach we tested the effects of a D1/D5 receptor agonist on multiple aspects of $\mathrm{Na}^{+}$channel gating in hopes of gaining new insights into this controversial issue.

\section{METHODS}

\section{SLICE PREPARATION}

The use and care of animals as well as protocol for slice preparation from anesthetized rats were approved by University of British Columbia Animal Care Committee.

Slices containing the medial prefrontal cortex (mPFC) were prepared from brains of 16-26 day old Sprague-Dawley rats. Animals were anesthetized with Isoflurane and killed by decapitation. The brain was quickly removed and placed in icecold oxygenated $\left(\mathrm{CO}_{2} 95 \%, \mathrm{O}_{2} 5 \%\right)$ cutting solution containing (in mM): $120 \mathrm{NaCl}, 20 \mathrm{NaHCO}_{3}, 10$ HEPES, $3 \mathrm{NaOH}, 2.5 \mathrm{KCl}$, $9 \mathrm{MgCl}_{2}, 0.5 \mathrm{CaCl}_{2}, 25 \mathrm{D}$-glucose, $0.4 \mathrm{~L}$-ascorbic acid. Coronal slices containing $\mathrm{mPFC}$ were cut on a vibratome at $300 \mu \mathrm{m}$. Dissected slices were kept at room temperature in a holding chamber in continuously oxygenated artificial cerebrospinal solution (ACSF) containing (in mM) $125 \mathrm{NaCl}, 25 \mathrm{NaHCO}_{3}$, $2.5 \mathrm{KCl}, 2 \mathrm{CaCl}_{2}, 1 \mathrm{MgCl}_{2}, 1.25 \mathrm{NaH}_{2} \mathrm{PO}_{4}, 25 \mathrm{D}$-glucose, $0.4 \mathrm{~L}$-ascorbic acid and 0.01 CNQX. The same composition ASCF was used for recording. After $>1 \mathrm{~h}$ incubation, slices were transferred to a recording chamber and perfused with continuously oxygenated ACSF at a rate of $1-1.5 \mathrm{ml} / \mathrm{min}$. Recordings were made at room temperature.

\section{PHARMACOLOGICAL AGENTS}

Stock solutions of CNQX, AP5 (Ascent Scientific, Princeton USA), TTX (Alomone labs, Israel) and SKF81297 (Sigma) were prepared in water, aliquoted and stored frozen at $-30^{\circ} \mathrm{C}$. Each drug was thawed and diluted to an appropriate concentration immediately before application.

\section{SINGLE CHANNEL RECORDINGS}

Layer $\mathrm{V}$ pyramidal cells were visualized in brain slices using infrared differential interference contrast optics (Axioskop Zeiss). Recordings were made from cell bodies, proximal apical dendrites (PD, 5-10 $\mu \mathrm{m}$ from soma) and proximal axons (PA, axon initial segment, 3-15 $\mu \mathrm{m}$ from soma) (Figure 1A). Pipettes were brought next to the neuron and very weak positive pressure was used to clean the surface before seal formation. Single channel recordings were made in cell-attached configuration. Patch pipettes were made from thick wall borosilicate glass capillaries with an outer diameter of $1.5 \mathrm{~mm}$. The internal surface of the glass capillaries was treated with Sigmacote and allowed to dry at room temperature at least 3 days before being used for manufacturing patch pipettes. This treatment significantly reduced capacitance and improved the quality of the seal, which approached values $>40 \mathrm{G} \Omega$. To reduce the number of single channels in a patch we used pipettes with resistances of 15-25 M $\Omega$ when filled with patch solution. The pipette solution for recording $\mathrm{Na}^{+}$channels contained the following (in mM): $130 \mathrm{NaCl}, 3 \mathrm{KCl}$, $2 \mathrm{CaCl}_{2}, 2 \mathrm{MgCl}_{2}, 0.1 \mathrm{CdCl}_{2}, 0.02 \mathrm{CNQX}, 0.05$ AP5, 10 D-glucose, 5 tetraethylammonium chloride, 14 -AP and 10 HEPES with a $\mathrm{pH}$ of 7.3. The pipette solution for recording delayed rectifier $\mathrm{K}^{+}$ channels contained the following (in $\mathrm{mM}$ ); $150 \mathrm{KCl}, 10 \mathrm{HEPES}$, $2 \mathrm{CaCl}_{2}, 2 \mathrm{MgCl}_{2}, 10$ D-glucose with a $\mathrm{pH}$ of 7.4.

Command voltage protocols were generated and singlechannel currents were acquired using an Axopatch $200 \mathrm{~B}$ amplifier with a Digidata 1320A analog-to-digital interface (Axon Instruments, CA). Capacitive transients were minimized using built-in circuits of the amplifier. Data were low-pass filtered at 2 or $5 \mathrm{kHz}$ and digitized at $50 \mathrm{kHz}$. The root mean square (RMS) noise was usually between 0.125 and 0.25 pA. Patches were held 20-40 $\mathrm{mV}$ more negative than the resting membrane potential and stepped to potentials $20-80 \mathrm{mV}$ more positive than the resting membrane potential.

\section{DATA ANALYSIS}

Data were analyzed using Clampfit 9.0 and 10.4 (pClamp package, Axon Instruments). Residual capacitance transits were nullified by off-line subtraction. For detection of single channels, state transitions with a minimum duration threshold of $0.05 \mathrm{~ms}$ were used. A list of idealized channel events was created and used for further analysis. For deriving single channel conductances, the amplitudes of well resolved square shape unitary events were chosen and the amplitudes of 15-25 unitary events measured at a given membrane potential were plotted against membrane potential for each patch. To calculate a slope conductance and extrapolated reversal potential, a linear regression analysis was performed in Statistica. For calculating the conductance of channels entering the prolonged bursting mode, we used the following depolarizing voltage ramp: from a holding potential $40 \mathrm{mV}$ more negative than resting membrane potential, the voltage was slowly increased to $80 \mathrm{mV}$ more positive than resting membrane potential at a rate of $0.2 \mathrm{mV} / \mathrm{ms}$. Traces without channel openings were averaged and this average trace was used for leak subtraction.

Ensemble-average traces were constructed by averaging 60 individual sweeps. The peak current at each potential was then converted to a conductance assuming a $\mathrm{Na}^{+}$reversal potential of $+60 \mathrm{mV}$. Least square fits to the Boltzmann function:

$$
y=A /\{1+\exp [(V m-V 1 / 2) / k]\}+C
$$

were made in Clampfit for each individual patch as well as for groups of patches. 
A

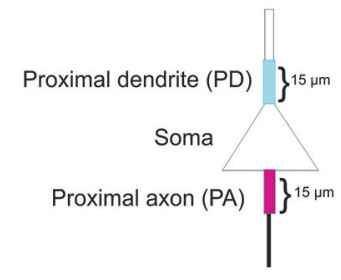

B

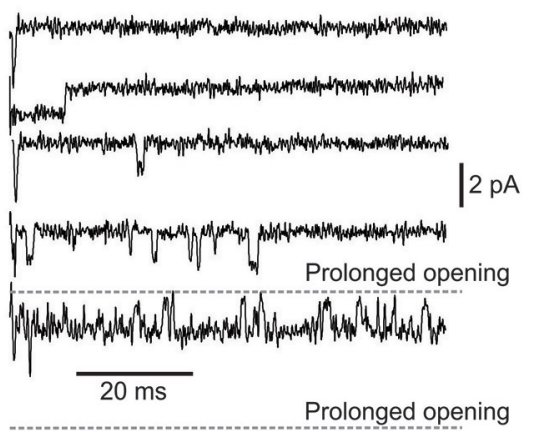

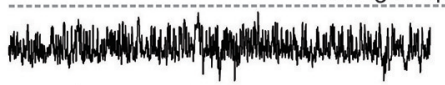

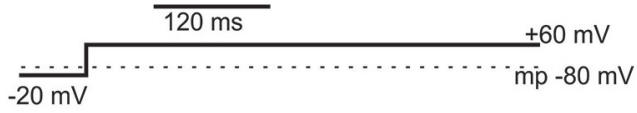

C

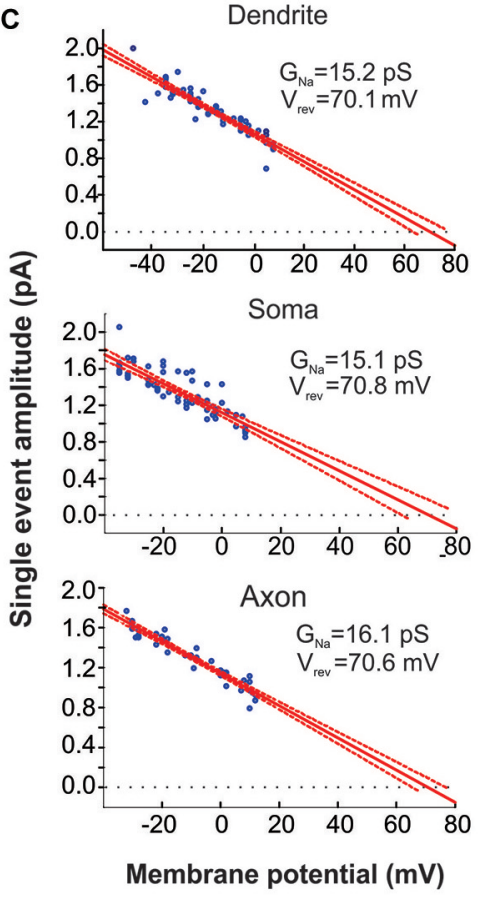

D

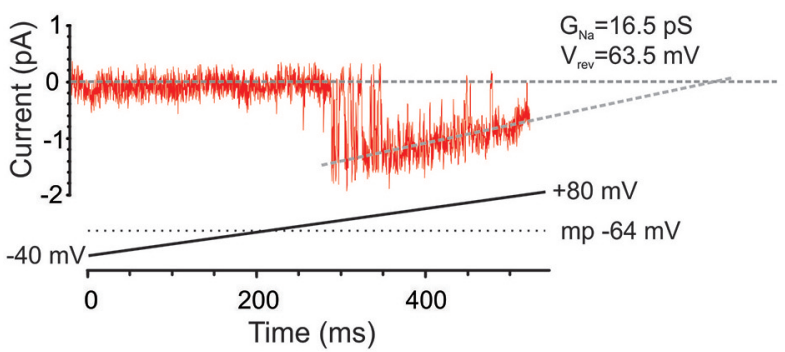

FIGURE 1 | Characteristics of $\mathrm{Na}^{+}$channel gating in $\mathrm{MPFC}$ neurons. (A) Schematic of the recording arrangement. Cell-attached patch-clamp recordings were made from the soma, the proximal dendrite (PD) or the proximal axon (PA), within 15 um of the soma. (B) Example traces from a cell-attached recording of $\mathrm{Na}^{+}$channel openings in the PD evoked by a $+60 \mathrm{mV}$ voltage step from a holding potential $-20 \mathrm{mV}$ below the presumed resting membrane potential of $-80 \mathrm{mV}$ (illustrated in the bottom schematic). Openings varied widely in duration. In some cases prolonged bursts were recorded that lasted hundreds of ms. (C) Group plot of the slope conductances derived from all recordings from the PD (top), soma (middle) or PA (bottom). The $x$-axis gives the transmembrane potential to which the patch was stepped (starting from a holding potential $-40 \mathrm{mV}$ hyperpolarized from rest) and the $y$-axis gives the average amplitude of all single openings
$>2 \mathrm{~ms}$ in duration evoked by the step. Each blue dot is data from a single patch and the red line is the regression fit (with 95\% confidence intervals) to the dots. The extrapolated slope conductance and reversal potentials are provided in the insets. (D) An example PD patch recording in which prolonged burst events were sufficiently frequent so as to allow for an investigation of the current throughout a voltage ramp. Channel openings began at an approximate transmembrane potential of $-45 \mathrm{mV}$ and decreased in amplitude as the driving force collapsed. The extrapolated slope conductance and reversal potential are given in the inset. The voltage ramp protocol is given in the bottom schematic and involved holding the patch $-40 \mathrm{mV}$ below rest and sweeping the voltage to $80 \mathrm{mV}$ above rest. The resting transmembrane potential, obtained after break in, is given by the dotted gray line.
A repeated measures ANOVA was used for statistical analysis of the voltage dependance of brief late $\mathrm{Na}^{+}$channel openings in the PD, soma and PA. A Student's $t$-test was used to determine the significance of the effect of the D1/D5 receptor agonist on ensemble currents. For statistical analysis of the effect of the D1/D5 receptor agonist on the brief late $\mathrm{Na}^{+}$channel openings and their gating, Student's $t$-tests with Holm-Bonferroni correction for multiple comparisons were performed. The values in the text and figures are presented as mean \pm SEM. The degrees of freedom are presented as the subscripts to $F$ and $t$.

\section{RESULTS \\ BASELINE CHARACTERISTICS OF UNITARY AND ENSEMBLE NA+ CHANNEL CURRENTS IN mPFC NEURONS}

The present study includes 22 cell-attached recordings from the soma, 34 from the PD and 13 from the proximal axon (PA; 
Figure 1). Even though all recordings were performed in cellattached mode, inward currents were shown as downward for consistency.

The ability to analyze and compare cell-attached recordings from different sites or under different conditions requires a reasonably accurate knowledge of the transmembrane potential. This can be difficult for cell-attached recordings. Following each recording, we applied suction to attain whole-cell mode and quickly recorded the membrane potential. The average resting voltage at break in was $-72.1 \pm 0.7 \mathrm{mV}, n=23$. The membrane potential at break-in was used as a correction in all of the analyses described below.

Since the pipette solution contained blockers of $\mathrm{K}^{+}$(TEA, $\mathrm{CsCl}$ ), $\mathrm{Ca}^{2+}$ currents (CdCl), AMPA (CNQX) and NMDA (AP5) currents, the remaining inwardly going single channel openings were assumed to be $\mathrm{Na}^{+}$currents. Accordingly, when the selective blocker of $\mathrm{Na}^{+}$channels, TTX (1 uM), was included in patch solution, no inward single channel openings were observed ( $n=11$, not shown). Examples of $\mathrm{Na}^{+}$channel gating in a PD cell-attached recording is shown in Figure 1B. From a presumed holding potential of $-100 \mathrm{mV}, 80 \mathrm{mV}$ voltage steps produced early channel openings as well as multiple late channel openings. Openings included single brief openings, short bursts of brief openings as well as prolonged burst openings. The amplitudes of the brief yet fully resolved late (>20 ms after voltage step initiation) single openings were quantified across a family of voltage steps and plotted against the membrane potential (Figure 1C). The slope of regression line gave us the conductance of unitary openings and the extrapolated reversal potential. The reversal potentials calculated for 11 patches were between +68.8 and $+79.1 \mathrm{mV}$, with an average $+73.1 \pm 0.96 \mathrm{mV}, n=11$. This is very close to the calculated Nernst equilibration potential for $\mathrm{Na}^{+}$current at $25^{\circ} \mathrm{C}$ which would be +66.9 to $76 \mathrm{mV}$ with an external $\mathrm{Na}^{+}$concentration (i.e., the patch solution) of $135 \mathrm{mM}$ and assuming an internal $\mathrm{Na}^{+}$concentration of 7-10 mM.

Using the same approach we also calculated the slope conductances of the $\mathrm{Na}^{+}$channels recorded from the three regions. The average conductance of late single events recorded from $\mathrm{PD}$ recordings was $15.2 \pm 3.8 \mathrm{pS}, n=8$, from somatic recordings was $15.1 \pm 3.2 \mathrm{pS}, n=8$ and from PA recordings was $16.1 \pm 4.8 \mathrm{pS}, n=7$. While combining many patches in this manner was useful in that it produced robust overall estimates, it could occlude subtle differences in the individual slope conductances present in a given patch. While most patches had $\mathrm{Na}^{+}$channels with conductances of $\sim 16 \mathrm{pS}$, there were a few patches from the axon and dendrite (but not soma) that exhibited a slope conductance of $\sim 19 \mathrm{pS}$. These conductance values are very consistent with past studies of $I_{\text {Nap }}$ in cultured cortical pyramidal neurons (Magistretti et al., 1999a,b; Magistretti and Alonso, 2006).

In addition to the brief late openings, the channels sometimes exhibited prolonged burst openings that could last several hundreds of milliseconds (Figure 1B). To attain a measure of the conductance of channels displaying sustained burst openings, we exploited the prolonged nature of these bursts and recorded channel openings during depolarizing voltage ramps from a transmembrane potential of $-120 \mathrm{mV}$ to $0 \mathrm{mV}$. An example of one of these prolonged burst openings recorded from a dendritic patch during a depolarizing ramp is shown in Figure 1D. Regression analysis yielded a slope conductance of $16.5 \mathrm{pS}$ for the patch shown in Figure 1D and an average value of $16.7 \pm 2.96 \mathrm{pS}$ for 5 additional $\mathrm{PD}$ patches. This conductance value was very consistent with what was obtained from single events shown in Figure 1C. Therefore, the present results suggest that $I_{\mathrm{Nap}}$ in layer $\mathrm{V}$ PFC neurons can be produced by a population of $\sim 16 \mathrm{pS} \mathrm{Na}^{+}$channels that enter a distinct prolonged gating mode, consistent with past studies in neurons from other cortical regions (Alzheimer et al., 1993).

All patches contained multiple channels as manifest by the appearance of overlapping multiple openings at the beginning of the depolarizing steps. To combine or compare data obtained from different patches we estimated the number of channels in each patch using peak current variance methods. Assuming that all $\mathrm{Na}^{+}$channels within a patch are independent and have uniform conductance and open probability, the number of channels $(N)$ and the peak open probability $\left(P_{\mathrm{o}}\right)$ can be derived as follows (Kimitsuki et al., 1990; Astman et al., 2006):

$$
\begin{aligned}
N & =I_{\text {peak }} / i P_{\mathrm{o}} \\
P_{\mathrm{o}} & =1-\sigma_{\text {peak }}^{2} / i I_{\text {peak }}
\end{aligned}
$$

where $I_{\text {peak }}$ is the average $\mathrm{Na}^{+}$current value at the peak, $\sigma^{2}$ peak is the peak $\mathrm{Na}^{+}$current variance and $\mathrm{i}$ is the unitary single channel current amplitude.

To estimate the number of channels in each patch we measured the amplitude of the peak current during a $60 \mathrm{mV}$ depolarizing step as well as the later unitary single channel currents that occurred from $20 \mathrm{~ms}$ to the end of the step. Across the entire data set, there was an average of $5.9 \pm 0.8, n=16$ channels/patch in somatic patches, $7.6 \pm 1.5, n=18$ channels/patch in PD patches and $9.5 \pm 1.8, n=13$ channels/patch in PA patches. For the analysis of late openings, we normalized the number of openings and open probability obtained for each patch based on the estimated number of channels in the patch.

The late channel openings were counted starting $20 \mathrm{~ms}$ after the beginning of the depolarizing step. The average number of late openings per channel per sweep was calculated by dividing the number of all late openings by the number of channels in the patch and by the number of depolarizing sweeps. Open probability of late openings was calculated as a ratio of the total open time during depolarizing steps relative to the total time of the depolarization and then divided by the estimated number of channels in the patch. To obtain the voltage dependance of late openings, patches were held $20 \mathrm{mV}$ more negative than the resting membrane potential and stepped to potentials $20-80 \mathrm{mV}$ more positive than the resting membrane potential in $5 \mathrm{mV}$ intervals (corrected based on the resting membrane potential at break-in).

To derive mean values of the number of openings, dwell time and $P_{\mathrm{o}}$ we combined data from different patches in $5 \mathrm{mV}$ bins. The mean number of openings, dwell time and $P_{\mathrm{o}}$ for events recorded from the three regions are shown in Figure 2. We included in the analysis all late single openings or late openings 
that appeared as a part of brief bursts. Bursts with durations longer than $40 \mathrm{~ms}$ were excluded from this analysis but will be dealt with below. For all regions the largest number of openings was observed at an estimated transmembrane voltage of -30 to $-40 \mathrm{mV}$. The mean number of openings was not significantly different for the three areas $\left(F_{(2,8)}=0.98, p=0.41\right)$. The mean dwell time progressively increased with larger step voltages and attained an asymptote at $\sim-20 \mathrm{mV}$. Again the three regions did not differ in terms of mean dwell time $\left(F_{(2,8)}=1.77, p=0.22\right)$. Finally the mean $P_{\mathrm{o}}$ peaked at $\sim-30 \mathrm{mV}$ and also did not show a difference between the regions after Holm-Bonferroni correction for multiple comparisons $\left(F_{(2,8)}=4.3, p=0.049\right)$.

Next we characterized the ensemble currents produced by summing over numerous single sweeps (Figure 3A). For these experiments patches were held $-40 \mathrm{mV}$ below rest and a series of voltage steps $20-80 \mathrm{mV}$ above rest were delivered. Even for patches with the smallest $\mathrm{N}$, an ensemble current could always be observed by averaging hundreds traces following a voltage step to $-20 \mathrm{mV}$. However, for constructing I-V plots we only used patches containing more than 6 channels. Figure 3B describes the $\mathrm{I}-\mathrm{V}$ relationship of the ensemble current depicted in Figure 3A. We used two approaches to calculate the average half activation voltage $\left(V_{\text {mid }}\right)$ for each region. First, Boltzmann fits to the normalized conductances for each patch were performed and the average $V_{\text {mid }}$ was then calculated. The resultant $V_{\text {mid }}$ values were not different between regions: $-16.1 \pm 1.11 \mathrm{mV}, n=6$ for the PD vs. $-16.4 \pm 2.65 \mathrm{mV}, n=5$ for the soma vs. 16.5 $\pm \mathrm{mV}, n=5$ for the PA $\left(F_{(2,14)}=0.04, p=0.96\right)$. Second, for each region we combined the normalized conductance values from all single patches into a single plot and then performed the Boltzmann fits (Figure 3C). The obtained values of $V_{\text {mid }}$ were similar to the first approach and were $-16.4 \pm 0.65 \mathrm{mV}$ for the PD, $-16.2 \pm 1.04 \mathrm{mV}$ for the soma and $16.14 \pm 0.72$ for the PA.

\section{D1/D5 RECEPTOR MODULATION OF UNITARY AND ENSEMBLE NA ${ }^{+}$ CHANNEL CURRENTS IN mPFC NEURONS}

Prior to analyzing the effects of the D1/D5 receptor agonist SKF81297 on $\mathrm{Na}^{+}$channel gating, it was important to determine whether the drug affected the membrane potential, since a change in voltage would alter all voltage-dependent measurements. To test this the $\mathrm{K}^{+}$reversal potential was analyzed under baseline conditions and following the administration of SKF81297 (3$5 \mu \mathrm{M})$ in the bath. The delayed rectifier $\mathrm{K}^{+}$current was chosen because it is very prominent in cell-attached recordings from mPFC neurons in the absence of TEA. To measure changes in $\mathrm{K}^{+}$reversal potential, we recorded the delayed rectifier $\mathrm{K}^{+}$channel using a patch solution with a potassium concentration of $150 \mathrm{mM}$. This was close to the internal potassium concentration, thereby bringing the $\mathrm{K}^{+}$reversal potential in the patch close to 0 . We used the following ramping voltage protocol: from the resting membrane potential, the voltage was slowly increased to $120 \mathrm{mV}$ more positive than the resting membrane potential at a rate of $0.2 \mathrm{mV} / \mathrm{ms}$. By delivering such ramping protocols it allowed us directly record the reversal potential of the current with an accuracy of $\pm 0.5 \mathrm{mV}$. In 5 patches tested, the $\mathrm{K}^{+}$reversal potential changed by less than $1 \mathrm{mV}$ (range $-0.8 \mathrm{mV}+0.6 \mathrm{mV}$ ) following D1/D5 receptor agonist administration (Figure 4). This indicated that any impact of SKF81297 on membrane potential was negligible and should not contaminate our analysis of its effects on $I_{\text {Nap. }}$.

The effect of the D1/D5 receptor agonist on $\mathrm{Na}^{+}$channel gating was assessed in two ways. Since it was difficult to attain a viable patch with unwavering seal resistance for more than $\sim 15 \mathrm{~min}$, there was usually insufficient opportunity to measure $\mathrm{Na}^{+}$channel gating across a variety of voltage steps under baseline and SKF81297 conditions in the same patch. Therefore, we either tested a single voltage step under baseline conditions and following SKF81297 in a single patch, or we performed a series of voltage steps in one group of patches under control conditions and repeated the same voltage steps in a different group of patches that received SKF81297 immediately upon seal stabilization.

The average ensemble response from a single PD patch under baseline and SKF81297 conditions is shown in Figure 5A for a voltage step to a transmembrane potential of $-20 \mathrm{mV}$. It shows a moderate increase in the ensemble current in response to D1/D5 receptor stimulation. Figure 5B represents group data for the patches from the three regions. The amplitudes of the ensemble
A

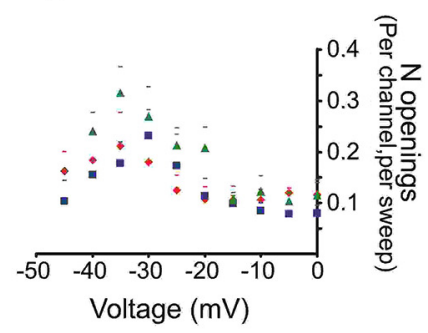

B

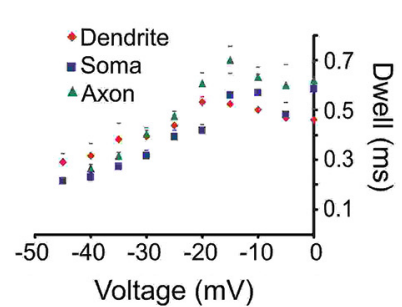

C

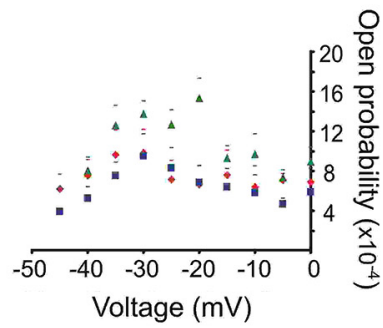

FIGURE 2 | Quantitative analysis of the late $\mathrm{Na}^{+}$channel openings. The late channel openings were counted starting $20 \mathrm{~ms}$ after the beginning of the depolarizing step. Each panel provides the average group data from PD patches (red diamonds), somatic patches (blue squares) or PA patches (green triangles). The SEM is given by the corresponding colored lines. (A) The number of late $\mathrm{Na}^{+}$channel openings (per channel, per sweep) $(N)$ (B) dwell time or $(\mathbf{C})$ open probability $\left(P_{\mathrm{o}}\right)$ of late $\mathrm{Na}^{+}$channel openings for each region as a function of transmembrane voltage. 
A

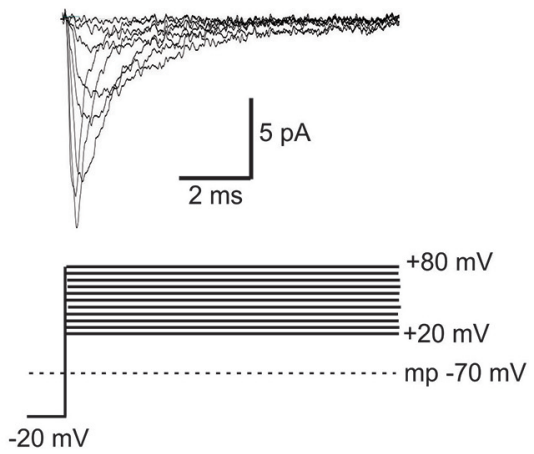

FIGURE 3 | Properties of ensemble $\mathrm{Na}^{+}$currents. (A) Representative recordings (top) from a PD patch showing the ensemble $\mathrm{Na}^{+}$currents evoked by various amplitude voltage steps from a holding potential $-20 \mathrm{mV}$ hyperpolarized from rest. Each line is an average of $>60$ individual traces. The transmembrane potential is given by the gray dotted line in the bottom schematic. (B) The I-V plot of the patch
B

C
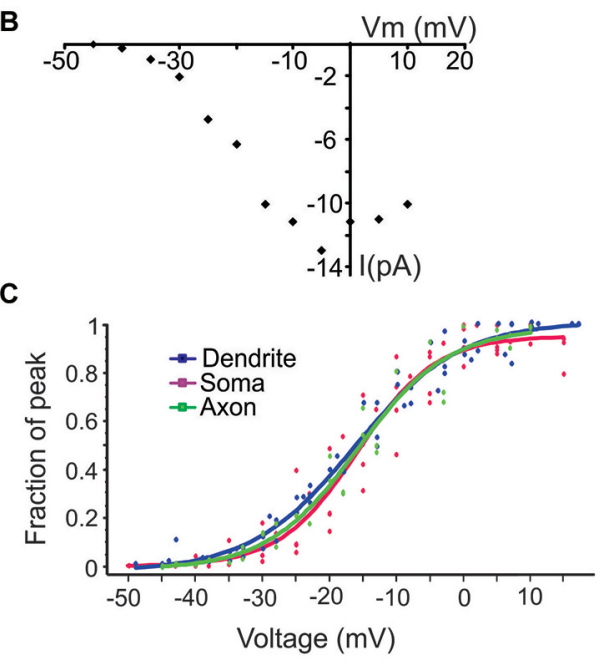

shown in (A). In this graph the $x$-axis is the transmembrane voltage to which the patch was stepped and the $y$-axis is the peak single channel current. (C) Plots of normalized peak conductances as a function of steps to various transmembrane potentials for groups of patches from the PD (blue), soma (purple) and PA (green). Each dot represents the normalized conductance for a single patch. The lines are Boltzmann fits. currents were increased by SKF81297 in PD patches by $28 \pm 8 \%$, $n=6$, in somatic patches by $23 \pm 17 \%, n=6$ and in PA patches by $25 \pm 7 \%, n=5$.

The normalized conductances were then plotted as a function of voltage for the group of patches recorded under baseline conditions and a different group of patches recorded in the presence of $3 \mu \mathrm{M}$ SKF81297. Boltzmann fits revealed that SKF81297 shifted the $\mathrm{Na}^{+}$current activation curve leftward in all three regions (Figure 5C). The same analysis was rerun in a slightly different manner in that the Boltzmann fits were performed first on each patch and then the results were combined. This also showed that SKF81297 had a significant effect on $V_{\text {mid }}$ in the PD $(-16.3 \pm 2.7 \mathrm{mV}, n=6$ in control vs. $-22.6 \pm$ $3.6 \mathrm{mV}, n=7$ in SKF81297, $\left.t_{11}=3.79, p<0.01\right)$, the soma $(-16.1 \pm 4.4 \mathrm{mV}, n=5$ in control vs. $-21.4 \pm 3.2 \mathrm{mV}, n=5$ in SKF81297 $\left.t_{8}=2.43, p<0.05\right)$ and the PA $(-16.6 \pm 2.5 \mathrm{mV}$, $n=5$ in control vs. $-21.6 \pm 0.75 \mathrm{mV}, n=5$ in SKF81297, $\left.t_{8}=4.44, p<0.01\right)$. There were no significant differences in the average maximal current amplitudes between the control group of patches and the patches treated with SKF81297 (PD: $7.3 \pm 4.8 \mathrm{pA}, n=6$ in control vs. $10.3 \pm 5.2 \mathrm{pA}, n=7$ in SKF81297, $t_{11}=1.1, p=0.29$ ) (soma: $6.7 \pm 1.8 \mathrm{pA}, n=5$ in control vs. $6.1 \pm 1.8 \mathrm{pA}, n=5$ in SKF81297, $t_{8}=0.54, p=0.6$ ) (PA:15.1 $\pm 8.2 \mathrm{pA}, n=5$ in control vs. $14.04 \pm 2.9 \mathrm{pA}, n=5$ in SKF81297, $\left.t_{8}=0.21, p=0.84\right)$. Therefore, based on this analysis of ensemble currents, D1/D5 receptor activation caused a greater $\mathrm{Na}^{+}$current for the same voltage step because it produced a leftward shift in activation, rather than an absolute increase in the peak channel conductance. In these experiments, the average membrane potential at break in was $-71.8 \pm 0.7 \mathrm{mV}, n=18$ for all cells in the control group and did not differ significantly from the average membrane potential at break-in for all cells treated with SKF81297 $(-71.2 \pm 0.4 \mathrm{mV}, n=18)\left(t_{34}=-0.8\right.$, $p=0.43$ ).

Next we investigated the effects of SKF81297 on multiple late single channel openings. In these experiments we utilized $100 \mathrm{~ms}$ and $550 \mathrm{~ms}$ depolarizing voltage steps. Since we didn't find any difference in the late $\mathrm{Na}^{+}$channel openings between these two groups, they were pooled. The number of late openings was calculated by dividing the number of all late openings by the number of channels in the patch and by the number of depolarizing sweeps and then scaled to a $80 \mathrm{~ms}$ length of sweep. Figure 6A shows example traces from a dendritic patch under baseline conditions and following the activation of D1 receptors by SKF81297. Across the population of patches recorded at voltage steps to transmembrane potentials of -40 to $-50 \mathrm{mV}$, SKF81297 significantly increased the number of openings in the PD $(0.17$ \pm 0.036 in control vs. $0.24 \pm 0.042$ in SKF81297, $t_{9}=5.96$, $p=0.0001)$, but not the soma $(0.24 \pm 0.04$ in control vs. 0.29 \pm 0.051 in SKF81297, $\left.t_{8}=1.15, p=0.14\right)$ or PA $(0.148 \pm 0.021$ in control vs. $0.18 \pm 0.035$ in SKF81297, $\left.t_{6}=1.84, p=0.057\right)$ (Figure 6B). SKF81297 also significantly increased $P_{\mathrm{o}}$ in the $\mathrm{PD}(0.00165 \pm 0.00054$ in control vs. $0.00217 \pm 0.00068$ in SKF81297, $\left.t_{9}=3.75, p<0.002\right)$ the soma $(0.00155 \pm 0.0003$ in control vs. $0.00217 \pm 0.00053$ in SKF81297, $\left.t_{8}=2.41, p=0.045\right)$ but not the PA $(0.00168 \pm 0.00044$ in control vs. $0.00160 \pm$ 0.00028 in SKF81297, $t_{6}=-0.33, p=0.37$ ) (Figures 6B,C). The overall dwell time did not differ under baseline vs. SKF81297 (Figures 6B-D) in the PD $(0.663 \pm 0.081 \mathrm{~ms}$ in control vs. 0.656 $\pm 0.068 \mathrm{~ms}$ in SKF81297, $\left.t_{9}=0.31, p=0.38\right)$, the soma $(0.519$ $\pm 0.058 \mathrm{~ms}$ in control vs. $0.621 \pm 0.072 \mathrm{~ms}$ in SKF81297, $t_{8}$ $=2.52, p=0.05)$ or the PA $(0.944 \pm 0.158 \mathrm{~ms}$ in control vs. 


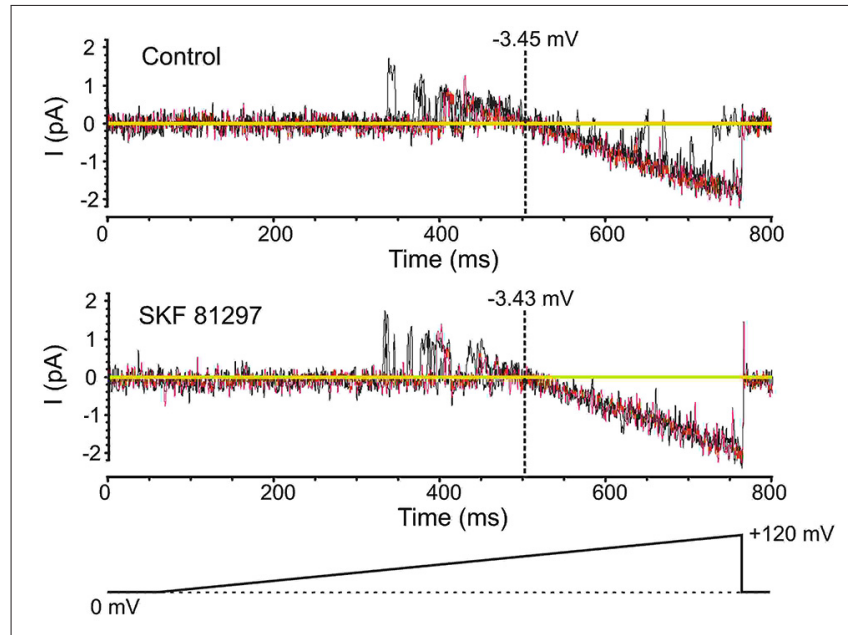

FIGURE 4 | Testing the effects of SKF81297 on membrane potential based on an analysis of $\mathbf{K}^{+}$channels. To get a surrogate measure of transmembrane voltage in cell-attached mode, the reversal potential for delayed rectifier $\mathrm{K}^{+}$channel openings was used. For these experiments, the patch solutions were altered by removing $\mathrm{K}^{+}$channel blockers and matching the $\left[\mathrm{K}^{+}\right]$in the patch pipette to the intracellular concentration, yielding a reversal potential near $0 \mathrm{mV}$. Voltage ramps started at the resting membrane potential and moved to $+120 \mathrm{mV}$ depolarized from rest (bottom schematic). The resting membrane potential for the presented cell was $-80 \mathrm{mV}$. Multiple continuous openings were evoked. These openings started as outward but flipped to inward as the patch was depolarized. The reversal occurred at a transmembrane potential of $-3.45 \mathrm{mV}$ (top).

Following the bath application of SKF81297 (3-5 $\mu \mathrm{M})$, the reversal occurred at a transmembrane potential of $-3.43 \mathrm{mV}$ (bottom). Black and red lines are single sweeps. Sweeps with channel openings across a wide range of voltages were chosen. The background current was subtracted.

$0.982 \pm 0.119 \mathrm{~ms}$ in SKF81297, $t_{6}=-1.27, p=0.12$ ). Therefore, D1/D5 receptor stimulation mainly increased the probability that $\mathrm{Na}^{+}$channels open in the PD and to a lesser extent in the soma.

In order to confirm that the above effect of SKF81297 on $\mathrm{Na}^{+}$ channel gating in the PD was due to D1/D5 receptor activation, we tested if the D1/D5 receptor antagonist SCH23390 could block the effect of SKF81297 by applying SCH23390 $(3 \mu \mathrm{M}) 10 \mathrm{~min}$ before application of SKF81297(3 $\mu \mathrm{M})$. As can be seen in Figure 7, when the D1/D5 receptor agonist was applied in the presence of a D1/D5 receptor antagonist, no increase in either the number of late channel openings $(0.24 \pm 0.0049$ in SCH23390 control vs. $0.21 \pm 0.052$ in SKF81297 $\left.+\mathrm{SCH} 23390, t_{4}=2.23, p=0.09\right)$, the channel open probability $(0.0015 \pm 0.0003$ in SCH23390 control vs. $0.0014 \pm 0.0003$ in SKF81297 $\left.+\mathrm{SCH} 23390, t_{4}=4.7, p=0.009\right)$ or the dwell time $(0.457 \pm 0.037 \mathrm{~ms}$ in SCH23390 control vs. $0.486 \pm 0.073 \mathrm{~ms}$ in SKF81297 $\left.+\mathrm{SCH} 23390, t_{4}=0.66, p=0.55\right)$ was observed.

Next we compared the effects of the D1/D5 receptor agonist on the number of single openings vs. short bursts (prolonged bursts will be dealt with separately). For these analyses, short bursts were defined as multiple events occurring within an interval $<2 \mathrm{~ms}$ and with a total duration of less than $40 \mathrm{~ms}$. SKF81297 had marginal but non-significant effects on the number of isolated single events in the $\mathrm{PD}(0.082 \pm 0.015$ in control vs. $0.097 \pm 0.021$ in SKF81297, $\left.t_{9}=1.44, p=0.09\right)$, the soma $(0.089 \pm 0.016$ in control vs. $0.094 \pm 0.019$ in SKF81297, $\left.t_{8}=0.48, p=0.32\right)$ and the PA $\left(0.049 \pm 0.033\right.$ in control vs. $0.062 \pm 0.014$ in SKF81297, $t_{6}=$ $2.02, p=0.05)$. In contrast, the D1/D5 receptor agonist affected various burst metrics as shown in Table 1. Specifically, D1/D5 receptor stimulation significantly increased the total number of short bursts but only in the PD $(0.034 \pm 0.0093$ in control vs. $0.053 \pm 0.014$ in SKF81297, $t_{9}=6.07, p=0.00009$, Table 1). It also increased the total number of events that occurred within all the recorded bursts, but again only in the $\mathrm{PD}(0.097 \pm 0.028$ in control vs. $0.146 \pm 0.033$ in SKF81297, $t_{9}=5.43 p=0.0002$, Table 1). In contrast, the D1/D5 receptor agonist did not affect the average number of events/burst $(2.51 \pm 0.48$ in control vs. $2.78 \pm 0.75$ in SKF81297, $t_{9}=0.95, p=0.09$, Table 1). Thus the most likely explanation for these results was that SKF81297 caused an enhanced propensity of the $\mathrm{Na}^{+}$channel to open in bursts.

Finally we analyzed the effect of SKF81297 on prolonged bursts. First we analyzed the probability of channel entering the prolonged burst mode in patches subjected to $50 \mathrm{mV}$ depolarizing steps in control and during D1/D5 agonist application. For each region we calculated the number of prolonged openings for all patches and divided this number by the total number of traces multiplied by the number of channels in each patch. The probability of prolonged burst were higher during D1/D5 agonist application compared to the control in the PD $(0.000282$ in control vs. 0.000783 in SKF81297) and the soma (0.000212 in control vs. 0.001575 in SKF81297) but not the PA (0.000562 in control vs. 0.000631 in SKF81297). The low probability of prolonged bursts prevented us from performing statistical comparisons on these data. To overcome this, we calculated the probability of prolonged openings in control patches and in a separate group of patches that were exposed to the D1/D5 receptor agonist. Each patch was subjected to a series of steps to several membrane potentials, totaling $\sim 1000$ traces for each patch. The probability of prolonged bursts was calculated for each patch. Even though prolonged bursts were many fold more prevalent in the PA than the PD or soma under baseline conditions, SKF81297 increased the mean probability of their occurrence only in the PD $\left(t_{12}=6.42, p=0.0003\right)$ and the soma $\left(t_{10}=2.36, p=0.01\right)$ but not the PA $\left(t_{10}=-0.59, p=0.48\right)$ (Figure 8). In fact, the D1/D5 receptor agonist brought the prevalence of prolonged bursts in the PD and soma to the level of the PA under baseline conditions (Figure 8) and therefore selectively boosted the relative impact of $I_{\text {Nap }}$ in these regions. This tendency to promote prolonged bursting was the most significant effect of the D1/D5 receptor agonist on $I_{\text {Nap }}$ overall yet is very consistent with the conclusion above, that the drug also increased the propensity of $\mathrm{Na}^{+}$channels to open in shorter bursts.

Given these findings, it is of interest to consider how the recorded channels might contribute to the whole cell $I_{\text {Nap }}$ under control conditions and following SKF81297. The total $I_{\text {Nap }}$ current for each region was estimated based on $\mathrm{Na}^{+}$channel kinetics for steps to $-20 \mathrm{mV}$ using the following equation:

$$
I_{\text {Nap }}=N^{*}\left(P_{\mathrm{oB}}+P_{\mathrm{oL}}\right)^{*} i
$$




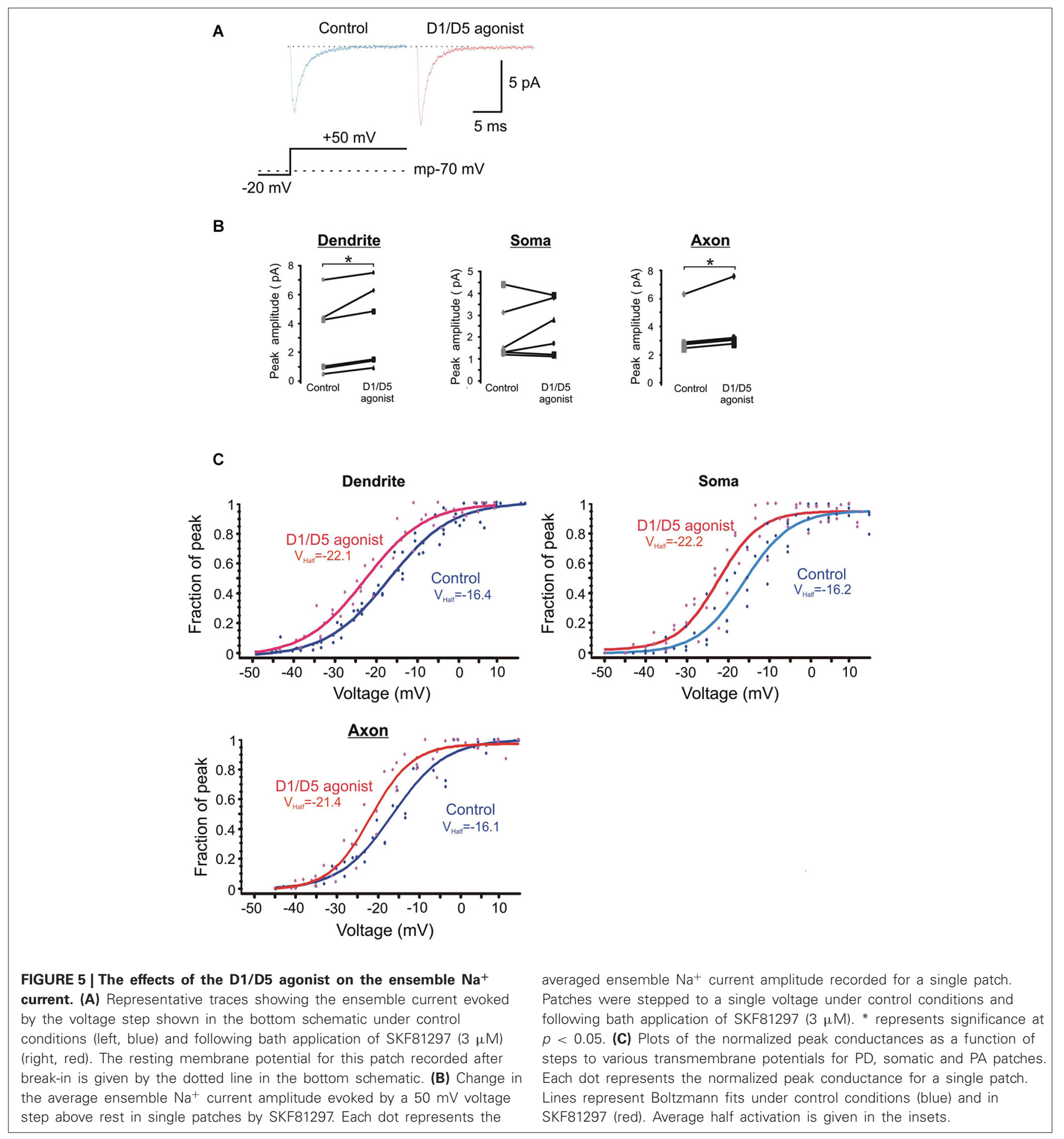

where $N$ is the total number of channels, $P_{\mathrm{OB}}$ is the open probability for brief openings, $P_{\mathrm{oL}}$ is the open probability for prolonged burst openings and $i$ is the unitary current amplitude. Although we estimated the number of channels in each patch from the actual recordings and used this value as a means to make conclusions about the single channel properties, our experimentally derived values for $N$ were not used in the calculation of the whole-cell $I_{\text {Nap }}$, since we were not exactly certain of the area of our patches and because the cytoskeletal properties of each region may differently affect the number of channels/patch (Kole et al., 2008). Rather, the determination of $\mathrm{N}$ was based on the published properties of cortical pyramidal neurons. Assuming the soma of a layer $\mathrm{V}$ cortical pyramidal cell is $\sim 20 \mu \mathrm{m}$ wide and $25 \mu \mathrm{m}$ long, it possesses a total surface area of $1099 \mu \mathrm{m}^{2}$ (for a cone). A PD $\sim 5 \mu \mathrm{m}$ in diameter and cylindrical, would have a surface area $314 \mu \mathrm{m}^{2}$ for a $20 \mu \mathrm{m}$ length, whereas 
A

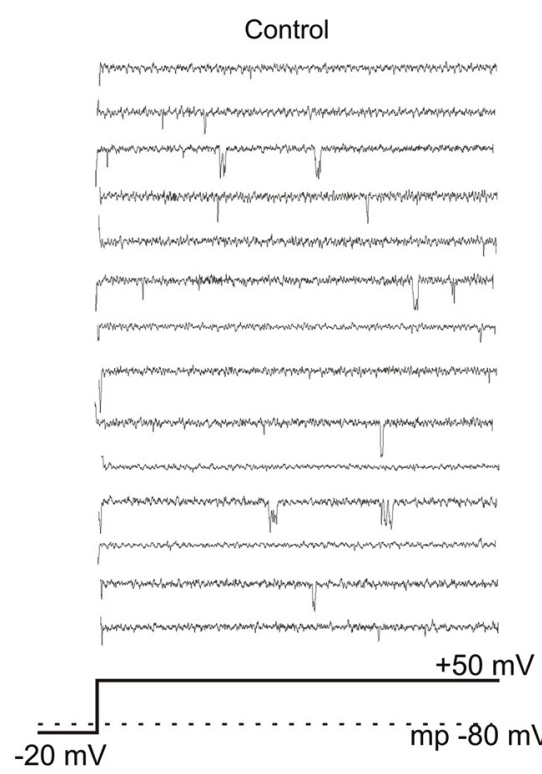

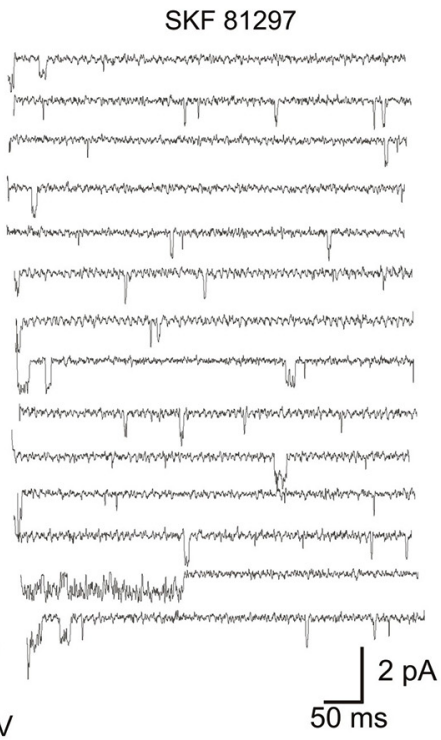

Dendrite

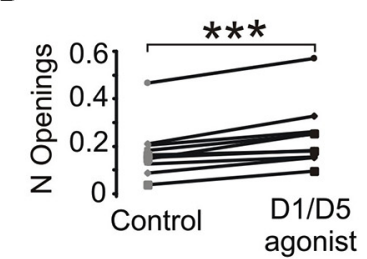

C

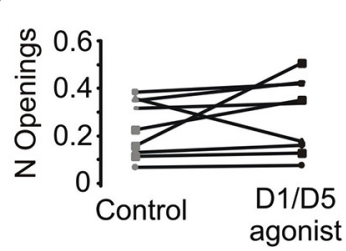

D

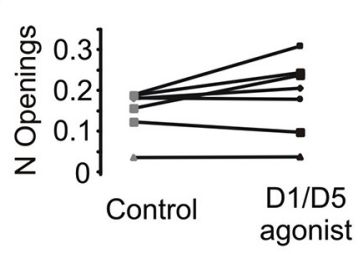

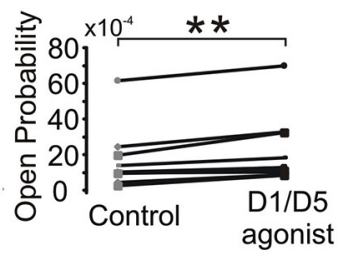

Soma

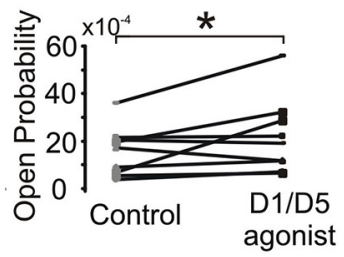

Axon

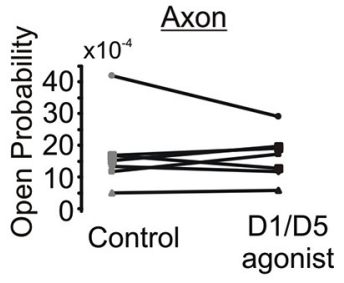

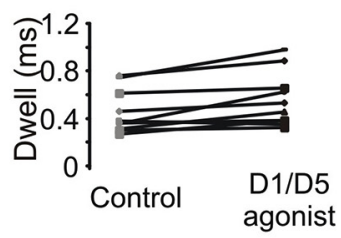

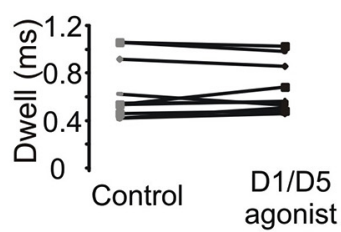

agonist

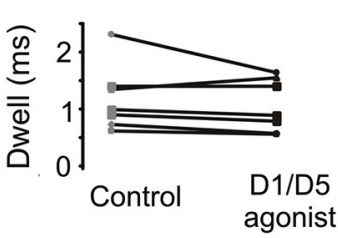

FIGURE 6 | The effect of a D1/D5 agonist on $\mathrm{Na}^{+}$channel gating. (A) Traces from a representative PD patch where isolated $\mathrm{Na}^{+}$channel openings were evoked by $70 \mathrm{mV}$ voltage steps from $-100 \mathrm{mV}$ to $-30 \mathrm{mV}$ (see bottom schematic). The resting potential is given by the dotted line in the bottom schematic. Control traces are shown at the left and traces from the same patch following bath application of SKF81297(3 $\mu$ M) are given at the right. (B) Quantification of the effects of the D1/D5 agonist on the late openings of $\mathrm{Na}^{+}$channels recorded from the PD: the number of late openings (per channel, per $80 \mathrm{~ms}$ ) (left), the open probability (middle) or the average dwell time (right). The late channel openings were counted starting $20 \mathrm{~ms}$ after the beginning of the depolarizing step. Each pair of connected dots is from a single patch. (C) Same as (B) but for patches recorded from the soma. (D) Same as (B) but for patches recorded from the PA.

*** represents significance at $p<0.001,{ }^{* *}$ represents significance at $p$ $<0.01$ and ${ }^{*}$ represents significance at $p<0.05$. an axon $\sim 1.2 \mu \mathrm{m}$ in diameter, would have a surface area of $75 \mu \mathrm{m}^{2}$ for a $20 \mu \mathrm{m}$ length. Sodium channel density has been estimated to be 5 per $\mu \mathrm{m}^{2}$ for the soma and PD (Hu et al., 2009).
The estimates of sodium channel density in the initial segment vary from three fold to $40-50$ fold higher than that of soma depending on methods used (Colbert and Pan, 2002; Kole et al., 

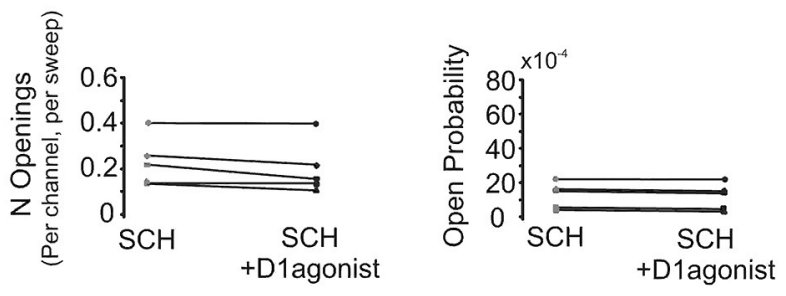

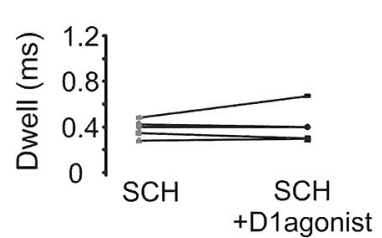

FIGURE 7| The D1/D5 receptor antagonist blocks the effect of the D1/D5 agonist on the late $\mathrm{Na}^{+}$channel openings. Quantification of the effects of the D1/D5 agonist (3 $\mu \mathrm{M}$ SKF81297) in the presence of the D1/D5 receptor antagonist $(3 \mu \mathrm{M} \mathrm{SCH} 23390)$ on the average number of late openings (per channel, per sweep) (left), the open probability (middle) and the average dwell time (right) of single $\mathrm{Na}^{+}$ channels recorded from the PD during a $70 \mathrm{mV}$ depolarizing step. Patches were held $20 \mathrm{mV}$ more negative than resting membrane potential. Each pair of connected dots represents data from the same patch.

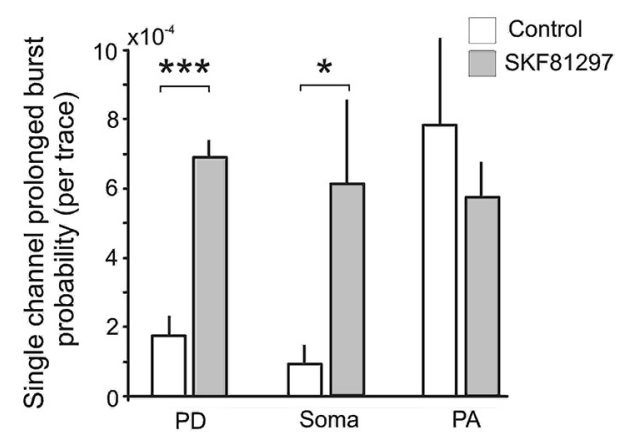

FIGURE 8 | The effects of the D1/D5 receptor agonist on prolonged burst openings. Prolonged burst openings were openings of $\mathrm{Na}^{+}$channels that lasted $>40 \mathrm{~ms}$. Such bursts were recorded when the patch was stepped from $-20 \mathrm{mV}$ below rest to $50 \mathrm{mV}$ above rest under contro conditions (open bars). Although the frequencies were highest in the PA under baseline conditions, SKF81297 (3 $\mu$ M) increased the probability that they would occur in the soma and PD but not in the PA. ${ }^{* *}$ represents significance at $p<0.001,{ }^{*}$ represents significance at $p<0.01$.

2008; Hu et al., 2009; Fleidervish et al., 2010). For our calculations we used a 10 times higher density of sodium channels in the PA compared to the soma, yielding 50 channels per $\mu \mathrm{m}^{2}$. Therefore, we estimate there would be $5495 \mathrm{Na}^{+}$channels at the soma, 1570 $\mathrm{Na}^{+}$channels in the first $20 \mu \mathrm{m}$ of the PD and $3750 \mathrm{Na}^{+}$channels in the first $20 \mu \mathrm{m}$ of the PA. In our recordings, the average unitary current amplitude at $-20 \mathrm{mV}$ across all the patches was $1.55 \mathrm{pA}$.
$P_{\text {oL }}$ was calculated using the following equation:

$$
P_{\mathrm{oL}}=\sum T_{\mathrm{j}} / \sum t_{\mathrm{j}} * n_{\mathrm{j}}
$$

where $T_{j}$ is the total time of all prolonged burst openings for the patch $j, t_{j}$ is the total duration of all recorded $-20 \mathrm{mV}$ steps for the patch $j$ and $n_{\mathrm{j}}$ is the number of channels in patch $j$.

The sums for each region were calculated across all patches subjected to $50 \mathrm{mV}$ depolarizing steps in control and during D1/D5 receptor agonist application. This gave $P_{\mathrm{oL}}$ values of 0.00028 for the PD, 0.00021 for the soma and 0.00042 for the PA. Values of $P_{\mathrm{oB}}$ were $0.00165,0.00155$ and 0.00168 for the PD, soma and $\mathrm{PA}$ respectively.

Based on these values, under control conditions the contribution of brief late openings to the total $I_{\text {Nap }}$ would be $\sim 4 \mathrm{pA}$ for the PD, $13.2 \mathrm{pA}$ for the soma and $9.8 \mathrm{pA}$ for the $\mathrm{PA}$ while the contribution of prolonged burst openings would be $\sim 0.68 \mathrm{pA}$ for the PD, $1.79 \mathrm{pA}$ for the soma and $2.44 \mathrm{pA}$ for the PA. The combined contribution of brief late openings and prolonged burst openings would be expected to produce a total $I_{\text {Nap }}$ of $\sim 4.68 \mathrm{pA}$ for the PD, $14.99 \mathrm{pA}$ for the soma and $12.2 \mathrm{pA}$ for the PA. The total $I_{\text {Nap }}$ across the three regions would be $\sim 31.9 \mathrm{pA}$, a value that is comparable to that obtained previously in acutely dissociated cortical pyramidal cells (see Maurice et al., 2001).

These calculations were repeated but using values obtained from the same patches in the presence of SKF81297. The $P_{\mathrm{oB}}$ values during D1/D5 receptor agonist application were 0.00217 , 0.00217 and 0.0016 for the PD, soma and PA respectively. And the

Table 1 | Analysis of various burst properties affected by the D1/D5 receptor agonist

\begin{tabular}{|c|c|c|c|c|c|c|c|c|}
\hline & \multicolumn{2}{|c|}{ PD } & \multicolumn{2}{|c|}{ Soma } & \multicolumn{2}{|c|}{ PA } & \multicolumn{2}{|c|}{ All } \\
\hline & $\%$ & $p$-value & $\%$ & $p$-value & $\%$ & $p$-value & $\%$ & $p$-value \\
\hline Single events & 19 & 0.09 & 12 & 0.32 & 22.3 & 0.05 & 17.5 & 0.02 \\
\hline Bursts & 97 & 0.00009 & 19.6 & 0.31 & 7 & 0.22 & 43.8 & 0.02 \\
\hline Event count/burst & 10.8 & 0.09 & 14 & 0.003 & 7.6 & 0.048 & 11 & 0.002 \\
\hline Events occurring in bursts & 98.7 & 0.0002 & 66 & 0.056 & 16.4 & 0.14 & 65.2 & 0.0006 \\
\hline
\end{tabular}

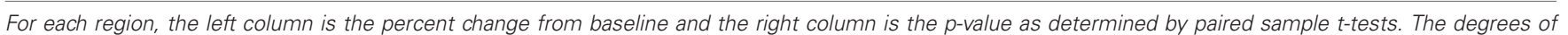
freedom are 9 for the dendrite, 8 for the soma and 6 for the axon. Alpha levels were determined by Holm-Bonferroni correction. 
calculated $P_{\mathrm{oL}}$ values were $0.00078,0.0015$ and 0.00047 for the $\mathrm{PD}$, soma and PA respectively. In this case, the $I_{\text {Nap }}$ produced by brief late openings would now be $\sim 5.28 \mathrm{pA}$ for the PD, $18.48 \mathrm{pA}$ for the soma and $9.3 \mathrm{pA}$ for the $\mathrm{PA}$, whereas the $I_{\mathrm{Nap}}$ resulting from prolonged burst openings would be $\sim 1.9 \mathrm{pA}$ for the PD, $12.8 \mathrm{pA}$ for the soma and $2.73 \mathrm{pA}$ for PA. The total $I_{\mathrm{Nap}}$ in SKF81297 would therefore be $\sim 7.18 \mathrm{pA}$ for the PD, $31.28 \mathrm{pA}$ for the soma and $12 \mathrm{pA}$ for the PA and when combined across the three regions would produce a total $I_{\mathrm{Nap}}$ of $\sim 50.46 \mathrm{pA}$. This represents a $60 \%$ increase over control. Furthermore, under control conditions prolonged bursts would contribute only $\sim 15 \%$ of total $I_{\mathrm{Nap}}$, whereas following SKF81297, the contribution of prolonged bursts would increase to $35 \%$.

\section{DISCUSSION}

The present study investigated the effects of the D1/D5 receptor agonist SKF81297 on single $\mathrm{Na}^{+}$channel gating recorded from the PD, soma and PA of deep layer mPFC neurons in acute brain slices. We found that SKF81297 shifted the activation of the early transient channel openings to more negative potentials in all three regions, while increasing the $P_{\mathrm{o}}$ of late openings and increasing prolonged burst probability mainly in the PD and to lesser extent in the soma. And as was estimated above, these effects would lead to an increase in the whole-cell $I_{\text {Nap }}$.

$I_{\text {Nap }}$ was first demonstrated in neocortical neurons by Stafstrom et al. (1982, 1985). It was initially thought that a prolonged $\mathrm{Na}^{+}$current could be produced by a window current attributable to the overlap between steady-state activation and inactivation (Attwell et al., 1979). Subsequently, $I_{\text {Nap }}$ has been commonly interpreted to result from brief forays of the fast $\mathrm{Na}^{+}$channel into a persistent or "noninactivating" gating mode during as little as $1 \%$ or less of all depolarizations (French and Gage, 1985; Patlak and Ortiz, 1985; French et al., 1990; Alzheimer et al., 1993; Taylor, 1993; Astman et al., 2006). It was proposed that in cortical layer $\mathrm{V}$ pyramidal cells, $I_{\text {Nap }}$ was generated primarily by $\mathrm{Na}^{+}$channels in the axon (Astman et al., 2006) and was attributed to the presence of Nav 1.6 channels (Caldwell et al., 2000; Hu et al., 2009) which enter the noninactivating gating mode more frequently and produce a significantly larger $I_{\mathrm{Nap}}$ than Nav1.1-1.2 channels localized in the soma and dendrites (Raman and Bean, 1997; Smith et al., 1998; Goldin, 2001; Rush et al., 2005). However, data obtained from Nav 1.6 knock-out mice revealed that although a large proportion of $I_{\text {Nap }}$ in layer $\mathrm{V}$ PFC cells is attributable to $\mathrm{Na}^{+}$channels containing the Nav 1.6 subunit, $\mathrm{Na}^{+}$channels with Nav1.1-1.2 subunits also contribute to $I_{\text {Nap }}$ (Maurice et al., 2001).

In the present study, the early transient current recorded in the PA displayed the same half activation as the early transient current recorded from soma and PD. Yet $\mathrm{Na}^{+}$channels recorded from PA displayed significantly larger open probabilities than for the PD and soma. Specifically, under control conditions the average probability of prolonged bursts in the $\mathrm{PD}$ and soma was 10 times lower than that of the late single or short burst openings. In contrast, in the PA the average probability of prolonged bursts was comparable to that of the late single or short burst openings. This implies that the prolonged bursts make a far greater contribution to the total $I_{\mathrm{Na}^{+}}$in the PA. It also suggests that while our recordings were in close proximity to each other, the regions were still functionally segregated in terms of their compliment of $\mathrm{Na}^{+}$channels.

In the studies of $\mathrm{Na}^{+}$channel gating in cultured entrorhinal layer II neurons, the average conductance of persistent burst openings was higher than that of early openings responsible for the transient $\mathrm{Na}^{+}$current ( $\sim 20$ vs. $\sim 15 \mathrm{pS}$ ) (Magistretti et al., 1999a,b; Magistretti and Alonso, 2006). While we did detect subgroups of $\mathrm{Na}^{+}$channels with different conductance levels, we found that channels with a conductance of $\sim 16 \mathrm{pS}$ could produce persistent openings. Magistretti et al. (2003) showed that single $\mathrm{Na}^{+}$channels can exhibit at least three "bursting states" of different mean durations but that each $\mathrm{Na}^{+}$channel preferentially operates predominately in a specific gating mode for protracted periods (Magistretti et al., 1999b; Magistretti and Alonso, 2006). These observations raise the perennial question of whether $I_{\text {Nap }}$ is mediated by differential gating in a common pool of $\mathrm{Na}^{+}$ channels or whether distinct $\mathrm{Na}^{+}$channels are responsible for $I_{\mathrm{Nat}}$ and $I_{\text {Nap. }}$. Magistretti et al. (1999b) argued for the possibility of something in between, as a subgroup of transient $\mathrm{Na}^{+}$channels may undergo some form of modulation to enter prolonged persistent gating modes. Supporting this contention, Szulczyk et al. (2012) recently showed that activation of D1/D5 dopamine receptors increased the availability of the fast $\mathrm{Na}^{+}$current without affecting current amplitude through a cAMP/PCA mechanism in $\mathrm{mPFC}$ neurons recorded in cell-attached mode. The present data also support the predictions of Magistretti et al. (1999b). On one hand, the single channel openings themselves were little changed as the single channel amplitude and dwell times in control and SKF81297 conditions were not significantly different. In spite of this, D1/D5 receptor activation significantly increased the number of openings as well as the propensity of the $\mathrm{Na}^{+}$channels to open in short and especially prolonged bursts in the PD and soma. In fact, prolonged burst probability increased three fold in the PD and nearly seven fold in the soma, which effectively brought the probabilities to the levels observed under baseline conditions in the PA. Thus D1/D5 receptor stimulation created a more uniform $I_{\text {Nap }}$ in mPFC neurons by equalizing basal differences in burst propensity across the soma, axon and dendrite.

Our estimates of the contribution of late openings of $\mathrm{Na}^{+}$ channels in the PD, soma and PA to the whole cell $I_{\text {Nap }}$ show that activation of D1/D5 receptors can lead to a significant increase in the whole cell $I_{\text {Nap }}$. Although useful as a means to help contextualize the significance of the single channel data, there are some caveats to these estimates that should be borne in mind. First, our estimates of $I_{\mathrm{Nap}}$ from the PA are not a reliable indicator of the total $I_{\text {Nap }}$ produced in the initial segment. As shown by Astman et al. (2006), most of the $I_{\mathrm{Nap}}$ in cortical pyramidal neurons is generated in the distal portion of the initial segment, well beyond where we recorded. In the proximal region of the axon, Nav 1.2 is dominant, rather than Nav 1.6 (Hu et al., 2009) that exits more distally. On the other hand, our estimates of $I_{\text {Nap }}$ from the soma and PD do not fall prey to this issue since the density of $\mathrm{Na}^{+}$channels does not tend to increase as one moves away from the soma into the dendrites. Therefore, if the peak whole cell $I_{\text {Nap }}$ recorded from the soma is $\sim 300$ pA (Astman et al., 2006), and we estimate that the three proximal compartments 
collectively generate a $\sim 30 \mathrm{pA} I_{\mathrm{Nap}}$, then the distal initial segment of the axon must generate the remaining $90 \%$ of the whole cell

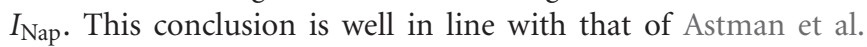
(2006). Hence, in order to attain a comprehensive understanding of dopamine modulation of $\mathrm{Na}^{+}$currents in mPFC neurons, similar cell-attached recordings from $\mathrm{Na}^{+}$channels in the distal axonal initial segment are still required. A second important point is that the "whole-cell" $I_{\text {Nap }}$ may not always be the key variable of interest as $I_{\mathrm{Nap}}$ generated in unique compartments might independently contribute to different aspects of signal processing. While the distal Nav 1.6 channels were proposed to be the main spike triggers, Nav 1.2 channels may primarily aid in spike back propagation from the axon to soma (Hu et al., 2009). Dendritic $\mathrm{Na}^{+}$channels might have a completely different function. For example, in an intact brain, overall membrane conductance is expected to be greater during periods of enhanced network activity, making neurons less electrically compact. This will result in a greater attenuation of synaptic potentials approaching the soma and axon along the apical dendrite. This may be one situation where D1/D5 receptor modulation plays a particularly important role, given the dramatic increase in the propensity of dendritic $\mathrm{Na}^{+}$channels to burst following SKF8127.

\section{THE EFFECTS OF DOPAMINE ON / Nap IN THE CONTEXT OF PAST WHOLE-CELL PATCH-CLAMP STUDIES}

While there is a growing consensus that dopamine acting via D1/D5 receptors increases the excitability of deep layer mPFC neurons, the present data shed some light on the sharp disagreement about whether this change in excitability is related to a change in $I_{\mathrm{Nap}}$. Initially, Geijo-Barrientos and Pastore (1995) used sharp intracellular recordings in the absence of blockers of other ionic currents to show that dopamine reduced a persistent inward current with properties consistent with $I_{\text {Nap }}$. Because other ion channels were not blocked, it was difficult to attribute the change directly to $I_{\text {Nap }}$ modulation however. Soon after Yang and Seamans (1996) used similar recording techniques but found that D1/D5 receptor agonists increased the TTX sensitive $\mathrm{Na}^{+}$plateau potential. A problem with this study was that since sharp somatic electrodes were used, it was impossible to control the voltage of the axo-somato-dendritic region adequately, and although various ion channel blockers were used, the nature of the modulation could not be precisely ascertained. Subsequently, Gorelova and Yang (2000) employed whole-cell patch-clamp recordings in the presence of blockers of most $\mathrm{K}^{+}$and $\mathrm{Ca}^{2+}$ channels. They found that D1/D5 receptor agonists shifted the activation of the whole cell $I_{\text {Nap }}$ leftward and slowed inactivation. Although much better voltage control could be attained with patch electrodes, it was still impossible to control voltage changes in the tiny axon and dendrites from the somatic electrode. Furthermore, a space clamp error by definition means that there is a difference in the potential from the clamped soma to the more distal neurites and therefore a flow of current. In extended pyramidal neuron under these conditions, that flow of current can resemble $I_{\text {Nap }}$ (White et al., 1995). Maurice et al. (2001) then attempted to circumvent these issues by performing recordings in acutely dissociated mPFC neurons. While they achieved much better voltage control than in past studies, even a length of axon as short as $10 \mu \mathrm{m}$ can be difficult to control from a somatic pipette (White et al., 1995). In addition, the reported absence of an effect of D1/D5 receptor agonists on $I_{\text {Nap }}$ could potentially have been the result of a loss/disruption of critical molecules needed for D1/D5 receptor modulation during the enzymatic/mechanical dissociation procedure. While Maurice et al. (2001) provided clear evidence that the D1-PKA pathway was functionally intact and able to modulate the fast $\mathrm{Na}^{+}$current in the dissociated neurons, the D1/D5 mediated increase in excitability of intact PFC neurons is thought to be mediated via a PKC and not a PKA mechanism (Chen et al., 2007). A PKC dependent increase in $I_{\text {Nap }}$ was also reported by Astman et al. (1998) who showed that PKC activation via phorbol esters greatly increased $I_{\text {Nap }}$ in somatosensory cortical neurons.

Finally a more recent attempt to address the issue was made by Rotaru et al. (2007). They employed a different approach as they investigated the D1/D5 receptor modulation of the EPSP amplification that is mediated mainly by $I_{\text {Nap }}$ (Stuart and Sakmann, 1995). They reported that D1/D5 receptor agonist reduced the amplification of EPSP waveforms and concluded that this was due to a reduction in $I_{\text {Nap }}$. While these authors showed that other currents, including $I_{\mathrm{h}}$ could impact EPSP amplification in separate experiments, they did not investigate the effects of a D1/D5 receptor agonist on EPSP amplification in the presence of an $I_{\mathrm{h}}$ blocker. Since D1/D5 agonists increase $I_{\mathrm{h}}$ (Rosenkranz and Johnston, 2006), this could potentially explain the apparent reduction in amplification by a D1/D5 agonist. The simultaneous modulation of $I_{\mathrm{h}}$ and $I_{\mathrm{Nap}}$ by D1/D5 receptor stimulation may be held within a tight balance and small differences in experimental procedures could conceivably shift the balance and thereby contribute to the differences across past studies.

The present study was designed to circumvent these past issues by using cell-attached recordings and showed that D1/D5 agonists increased $I_{\text {Nap }}$ mainly by promoting more robust bursting behavior in the PD and soma. While uncontaminated by the same issues that plagued past studies, we did not record from the distal initial segment where most of the $I_{\text {Nap }}$ is generated. Therefore, while the present data are quite clear in terms of how D1/D5 receptor activations modulates $\mathrm{Na}^{+}$channels proximal to the soma, general statements about how D1/D5 receptors modulate $I_{\text {Nap }}$ overall and under various realistic conditions, await future investigations.

\section{ACKNOWLEDGMENTS}

This research was supported by grants from CIHR.

\section{REFERENCES}

Alzheimer, C., Schwindt, P. C., and Crill, W. E. (1993). Modal gating of Na+ channels as a mechanism of persistent $\mathrm{Na}+$ current in pyramidal neurons from rat and cat sensorimotor cortex. J. Neurosci. 13, 660-673.

Astman, N., Gutnick, M. J., and Fleidervish, I. A. (1998). Activation of protein kinase $\mathrm{C}$ increases neuronal excitability by regulating persistent $\mathrm{Na}+$ current in mouse neocortical slices. J. Neurophysiol. 80, 1547-1551.

Astman, N., Gutnick, M. J., and Fleidervish, I. A. (2006). Persistent sodium current in layer 5 neocortical neurons is primarily generated in the proximal axon. J. Neurosci. 26, 3465-3473. doi: 10.1523/jneurosci.4907-05.2006

Attwell, D., Cohen, I., Eisner, D., Ohba, M., and Ojeda, C. (1979). The steady state TTX-sensitive ("window") sodium current in cardiac Purkinje fibres. Pflugers Arch. 379, 137-142. doi: 10.1007/bf00586939 
Caldwell, J. H., Schaller, K. L., Lasher, R. S., Peles, E., and Levinson, S. R. (2000). Sodium channel $\mathrm{Na}(\mathrm{v}) 1.6$ is localized at nodes of ranvier, dendrites and synapses. Proc. Natl. Acad. Sci. U S A 97, 5616-5620. doi: 10.1073/pnas.0900 34797

Chen, L., Bohanick, J. D., Nishihara, M., Seamans, J. K., and Yang, C. R. (2007). Dopamine D1/5 receptor-mediated long-term potentiation of intrinsic excitability in rat prefrontal cortical neurons: Ca2+-dependent intracellular signaling. J. Neurophysiol. 97, 2448-2464. doi: 10.1152/jn.00317.2006

Colbert, C. M., and Pan, E. (2002). Ion channel properties underlying action potential initiation in pramidal neurons. Nat. Neurosci. 5, 533-538. doi: 10. 1038/nn857

Durstewitz, D., and Seamans, J. K. (2008). The dual-state theory of prefrontal cortex dopamine function with relevance to catechol-o-methyltransferase genotypes and schizophrenia. Biol. Psychiatry 64, 739-749. doi: 10.1016/j.biopsych.2008. 05.015

Durstewitz, D., Seamans, J. K., and Sejnowski, T. J. (2000). Dopamine-mediated stabilization of delay-period activity in a network model of prefrontal cortex. J. Neurophysiol. 83, 1733-1750.

Fleidervish, I. A., Lasser-Ross, N., Gutnick, M. J., and Ross, W. N. (2010). Na+ imaging reveals little difference in action potential-evoked $\mathrm{Na}+$ influx between axon and soma. Nat. Neurosci. 13, 852-860. doi: 10.1038/nn.2574

Fleidervish, I. A., Libman, L., Katz, E., and Gutnick, M. J. (2008). Endogenous polyamines regulate cortical neuronal excitability by blocking voltage-gated $\mathrm{Na}+$ channels. Proc. Natl. Acad. Sci. U S A 105, 18994-18999. doi: 10.1073/pnas. 0803464105

French, C. R., and Gage, P. W. (1985). A threshold sodium current in pyramidal cells in rat hippocampus. Neurosci. Lett. 56, 289-293. doi: 10.1016/03043940(85)90257-5

French, C. R., Sah, P., Buckett, K. J., and Gage, P. W. (1990). A voltage-dependent persistent sodium current in mammalian hippocampal neurons. J. Gen. Physiol. 95, 1139-1157. doi: 10.1085/jgp.95.6.1139

Geijo-Barrientos, E., and Pastore, C. (1995). The effects of dopamine on the subthreshold electrophysiological responses of rat prefrontal cortex neurons in vitro. Eur. J. Neurosci. 7, 358-366. doi: 10.1111/j.1460-9568.1995.tb00331.x

Goldin, A. L. (2001). Resurgence of sodium channel research. Annu. Rev. Physiol. 63, 871-894. doi: 10.1146/annurev.physiol.63.1.871

Gorelova, N. A., and Yang, C. R. (2000). Dopamine D1/D5 receptor activation modulates a persistent sodium current in rat prefrontal cortical neurons in vitro. J. Neurophysiol. 84, 75-87.

Hu, W., Tian, C., Li, T., Yang, M., Hou, H., and Shu, Y. (2009). Distinct contributions of $\mathrm{Na}(\mathrm{v}) 1.6$ and $\mathrm{Na}(\mathrm{v}) 1.2$ in action potential initiation and backpropagation. Nat. Neurosci. 12, 996-1002. doi: 10.1038/nn.2359

Kimitsuki, T., Mitsuiye, T., and Noma, A. (1990). Maximum open probability of single $\mathrm{Na}+$ channels during depolarization in guinea-pig cardiac cells. Pflugers Arch. 416, 493-500. doi: 10.1007/bf00382681

Kole, M. H. P., Ilschner, S. U., Kampa, B. M., Williams, S. R., Ruben, P. C., and Stuart, G. J. (2008). Action potential generation requires a high sodium channel density in the axon initial segment. Nat. Neurosci. 11, 178-186. doi: 10. 1038/nn2040

Ma, J. Y., Catterall, W. A., and Scheuer, T. (1997). Persistent sodium currents through brain sodium channels induced by $\mathrm{G}$ protein betagamma subunits. Neuron 19, 443-452. doi: 10.1016/s0896-6273(00)80952-6

Ma, J. Y., Li, M., Catterall, W. A., and Scheuer, T. (1994). Modulation of brain Na+ channels by a G-protein-coupled pathway. Proc. Natl. Acad. Sci. U S A 91, 1235112355. doi: 10.1073/pnas.91.25.12351

Magistretti, J., and Alonso, A. (2006). Multiple conductance substates in pharmacologically untreated $\mathrm{Na}(+)$ channels generating persistent openings in rat entorhinal cortex neurons. J. Membr. Biol. 214, 165-180. doi: 10. 1007/s00232-006-0068-4

Magistretti, J., Ragsdale, D. S., and Alonso, A. (1999a). Direct demonstration of persistent $\mathrm{Na}+$ channel activity in dendritic processes of mammalian cortical neurones. J. Physiol. 521(Pt. 3), 629-636. doi: 10.1111/j.1469-7793.1999. 00629.x

Magistretti, J., Ragsdale, D. S., and Alonso, A. (1999b). High conductance sustained single-channel activity responsible for the low-threshold persistent $\mathrm{Na}(+)$ current in entorhinal cortex neurons. J. Neurosci. 19, 7334-7341.

Magistretti, J., Ragsdale, D. S., and Alonso, A. (2003). Kinetic diversity of singlechannel burst openings underlying persistent $\mathrm{Na}(+)$ current in entorhinal cortex neurons. Biophys. J. 85, 3019-3034. doi: 10.1016/s0006-3495(03)74721-3
Maurice, N., Tkatch, T., Meisler, M., Sprunger, L. K., and Surmeier, D. J. (2001). D1/D5 dopamine receptor activation differentially modulates rapidly inactivating and persistent sodium currents in prefrontal cortex pyramidal neurons. J. Neurosci. 21, 2268-2277.

Osorio, N., Cathala, L., Meisler, M. H., Crest, M., Magistretti, J., and Delmas, P. (2010). Persistent Nav1.6 current at axon initial segments tunes spike timing of cerebellar granule cells. J. Physiol. 588(Pt. 4), 651-670. doi: 10.1113/jphysiol. 2009.183798

Patlak, J. B., and Ortiz, M. (1985). Slow currents through single sodium channels of the adult rat heart. J. Gen. Physiol. 86, 89-104. doi: 10.1085/jgp.86.1.89

Raman, I. M., and Bean, B. P. (1997). Resurgent sodium current and action potential formation in dissociated cerebellar Purkinje neurons. J. Neurosci. 17, 4517-4526.

Rosenkranz, J. A., and Johnston, D. (2006). Dopaminergic regulation of neuronal excitability through modulation of Ih in layer V entorhinal cortex. J. Neurosci. 26, 3229-3244. doi: 10.1523/jneurosci.4333-05.2006

Rotaru, D. C., Lewis, D. A., and Gonzalez-Burgos, G. (2007). Dopamine D1 receptor activation regulates sodium channel-dependent EPSP amplification in rat prefrontal cortex pyramidal neurons. J. Physiol. 581(Pt. 3), 981-1000. doi: 10. 1113/jphysiol.2007.130864

Rush, A. M., Dib-Hajj, S. D., and Waxman, S. G. J. (2005). Electrophysiological properties of two axonal sodium channels, Nav1.2 and Nav1.6, expressed in mouse spinal sensory neurones. J. Physiol. 564(Pt. 3), 803-815. doi: 10. 1113/jphysiol.2005.083089

Smith, M. R., Smith, R. D., Plummer, N. W., Meisler, M. H., and Goldin, A. L. (1998). Functional analysis of the mouse Scn8a sodium channel. J. Neurosci. 18, 6093-6102.

Stafstrom, C. E., Schwindt, P. C., Chubb, M. C., and Crill, W. E. (1985). Properties of persistent sodium conductance and calcium conductance of layer $\mathrm{V}$ neurons from cat sensorimotor cortex in vitro. J. Neurophysiol. 53, 153-170.

Stafstrom, C. E., Schwindt, P. C., and Crill, W. E. (1982). Negative slope conductance due to a persistent subthreshold sodium current in cat neocortical neurons in vitro. Brain Res. 236, 221-226. doi: 10.1016/0006-8993(82) 90050-6

Stuart, G., and Sakmann, B. (1995). Amplification of EPSPs by axosomatic sodium channels in neocortical pyramidal neurons. Neuron 15, 1065-1076. doi: 10. 1016/0896-6273(95)90095-0

Szulczyk, B., Ksiażek, A., Ładno, W., and Szulczyk, P. (2012). Effect of dopamine receptor stimulation on voltage-dependent fast-inactivating $\mathrm{Na}(+)$ currents in medial prefrontal cortex (mPFC) pyramidal neurons in adult rats. Acta Neurobiol. Exp. (Wars) 72, 351-364.

Taylor, C. P. (1993). Na+ currents that fail to inactivate. Trends Neurosci. 16, 455 460. doi: 10.1016/0166-2236(93)90077-y

White, J. A., Klink, R., Alonso, A., and Kay, A. R. (1998). Noise from voltagegated ion channels may influence neuronal dynamics in the entorhinal cortex. J. Neurophysiol. 80, 262-269.

White, J. A., Sekar, N. S., and Kay, A. R. (1995). Errors in persistent inward currents generated by space-clamp errors: a modeling study. J. Neurophysiol. 73, 23692377.

Yang, C. R., and Seamans, J. K. (1996). Dopamine D1 receptor actions in layers VVI rat prefrontal cortex neurons in vitro: modulation of dendritic-somatic signal integration. J. Neurosci. 16, 1922-1935.

Conflict of Interest Statement: The authors declare that the research was conducted in the absence of any commercial or financial relationships that could be construed as a potential conflict of interest.

Received: 06 July 2014; accepted: 08 January 2015; published online: 12 February 2015. Citation: Gorelova N and Seamans JK (2015) Cell-attached single-channel recordings in intact prefrontal cortex pyramidal neurons reveal compartmentalized D1/D5 receptor modulation of the persistent sodium current. Front. Neural Circuits 9:4. doi: 10.3389/fncir.2015.00004

This article was submitted to the journal Frontiers in Neural Circuits.

Copyright (C) 2015 Gorelova and Seamans. This is an open-access article distributed under the terms of the Creative Commons Attribution License (CC BY). The use, distribution and reproduction in other forums is permitted, provided the original author(s) or licensor are credited and that the original publication in this journal is cited, in accordance with accepted academic practice. No use, distribution or reproduction is permitted which does not comply with these terms. 